\title{
Correction to: FASTA/Q data compressors for MapReduce-Hadoop genomics: space and time savings made easy
}

Umberto Ferraro Petrillo ${ }^{1 *}$, Francesco Palini ${ }^{1}$, Giuseppe Cattaneo ${ }^{2 \dagger}$ and Raffaele Giancarlo ${ }^{3 \dagger}$

\author{
The original article can be \\ found online at https://doi. \\ org/10.1186/s12859-021- \\ 04063-1. \\ *Correspondence: \\ umberto.ferraro@uniroma1.it \\ ${ }^{\dagger}$ Giuseppe Cattaneo and \\ Raffaele Giancarlo have \\ contributed equally to this \\ work \\ 1 Dipartimento di Scienze \\ Statistiche, Università di \\ Roma - La Sapienza, Rome, \\ Italy \\ Full list of author information \\ is available at the end of the \\ article
}

\section{Correction to: BMC Bioinformatics (2021) 22:144 \\ https://doi.org/10.1186/s12859-021-04063-1}

Following publication of the original article [1], the authors identified that the affiliations of Giuseppe Cattaneo and Raffaele Giancarlo were interchanged. The correct affiliations are given below.

The correct affiliation of Giuseppe Cattaneo is:

${ }^{2}$ Dipartimento di Informatica, Università di Salerno, Fisciano, Italy.

The correct affiliation of Raffaele Giancarlo is:

${ }^{3}$ Dipartimento di Matematica ed Informatica, Università di Palermo, Palermo, Italy.

The original article [1] has been corrected.

\section{Author details}

${ }^{1}$ Dipartimento di Scienze Statistiche, Università di Roma - La Sapienza, Rome, Italy. ${ }^{2}$ Dipartimento di Informatica, Università di Salerno, Fisciano, Italy. ${ }^{3}$ Dipartimento di Matematica ed Informatica, Università di Palermo, Palermo, Italy.

Published online: 15 February 2022

\section{Reference}

1. Ferraro Petrillo $U$, et al. FASTA/Q data compressors for MapReduce-Hadoop genomics: space and time savings made easy. BMC Bioinformatics. 2021;22:144. https://doi.org/10.1186/s12859-021-04063-1.

\section{Publisher's Note}

Springer Nature remains neutral with regard to jurisdictional claims in published maps and institutional affiliations.

(c) The Author(s) 2022. Open Access This article is licensed under a Creative Commons Attribution 4.0 International License, which permits use, sharing, adaptation, distribution and reproduction in any medium or format, as long as you give appropriate credit to the original author(s) and the source, provide a link to the Creative Commons licence, and indicate if changes were made. The images or other third party material in this article are included in the article's Creative Commons licence, unless indicated otherwise in a credit line to the material. If material is not included in the article's Creative Commons licence and your intended use is not permitted by statutory regulation or exceeds the permitted use, you will need to obtain permission directly from the copyright holder. To view a copy of this licence, visit http:// creativecommons.org/licenses/by/4.0/. The Creative Commons Public Domain Dedication waiver (http://creativecommons.org/publi cdomain/zero/1.0/) applies to the data made available in this article, unless otherwise stated in a credit line to the data. 